and immediately after sentence was pronounced, in a rambling address, said he allowed that it had been proved that opium in a solid form was present in the dark stains.

No hope of mercy was held out to him, and the last penalty of the law was carried out on Friday, 31st May.

Up to the Thursday morning, when the intimation arrived from the Home Secretary that the law must take its course, Chantrelle appeared to be careless of life, and indulged in continued bravado. The day before his execution, however, and subsequently on the morning of that day, a change came over him, and he acknowledged the many sins of his past life, but avoided reference to the crime for which he was about to expiate his life on the scaffold. As to this, he studiously refrained from declaring his innocence, and it was believed that, had longer time been allowed him, he would have been led to confess his guilt.

\title{
和art secont.
}

\section{REVIEWS.}

Fat and Blood: And How to Make Them. By S. Weir Mitchell, M.D., Member of the National Academy of Sciences; Physician to the Orthopædic Hospital and Infirmary for Diseases of the Nervous System; Fellow of the College of Physicians, Philadelphia, etc. etc. First English, from the Second American Edition. London : 1878, pp. 109.

THis little work, dedicated to John Forsyth Meigs, M.D., in grateful remembrance of many acts of friendly service, deserves a careful and thoughtful perusal. It is not an ephemeral production, written with a view to practice and popularity, as small books often are; it contains an original idea carefully elaborated, and is the outcome of marked and unusual success already achieved in the treatment of a large class of puzzling cases. The cases referred to are chiefly nervous women, who, as a rule, are thin, and lack blood. For some years, as the author tells us, he has been using, both in private and in hospital practice, certain methods of renewing the vitality of such feeble persons by a combination of entire rest and of excessive feeding, made possible by passive exercises obtained through the steady use of what he calls massage and electricity.

The following sketch will convey to the experienced practitioner the kind of case which Dr. Mitchell contemplates and seeks to relieve:- "A woman, most often between twenty and thirty, 
undergoes a season of trial, or encounters some prolonged strain. She undertakes the hard task of nursing a relative, and goes through this severe duty with the addition of emotional excitement, swayed by hopes and fears, and forgetful of self and of what every one needs in the way of air and food and change, when attempting this most trying task; or possibly it is mere physical strain, such as teaching. In another set of cases an illness is the cause, and she never rallies entirely, or else some local uterine trouble starts the mischief; and although this is cured, the doctor wonders that his patient does not get fat and ruddy again. But no matter how it comes about, the woman grows pale and thin, eats little, or, if she eats, does not profit by it. Everything wearies her-to sew, to write, to read, to walk-and by-and-by the sofa or the bed is her only comfort. Every effort is paid for dearly, and she describes herself as achirg and sore, as sleeping ill, and as needing constant stimulus and endless tonics. Then cumes the mischievous rôle of bromides, opium, chloral, and brandy. If the case did not begin with uterine troubles they soon appear, and are usually treated in vain, if the general means employed to build up the bodily health fail, as in many cases they do fail. The same remark applies to the dyspepsias and constipation which further annoy the patient, and embarrass the treatment. If such a person is emotional, she does not fail to become more so, and even the firmest women lose self-control at last under excessive feebleness. Nor is this less true of men; and I have many a time seen soldiers, who had ridden boldly with Sheridan, or fought gallantly with Grant, become, under the influence of painful nerve wounds, as irritable and hysterically emotional as the veriest girl. If no rescue comes, the fate of women thus disordered is at last the bed. They acquire tender spines, and furnish the most lament. able examples of all the strange phenomena of hysteria."

'The author goes on to paint in vivid colours the moral deterioration in the form of self-love, selfishness, and loss of self-control, which often supervenes in such cases, if they are of long standing, and not wisely managed by judicious relatives and friends. A great additional barrier thus rises unconsciously to all parties in the way of successful treatment. "It is the self-sacrificing love and over-careful sympathy of a mother, a sister, or some other devoted relative. Nothing is more curious, nothing more sad and pitiful than these partnerships between the sick and selfish and the sound and over-loving. By slow but sure degrees the healthy life is absorbed by the sick life, in a manner more or less injurious to both, until, sometimes too late for remedy, the growth of the evil is seen by others. Usually the person withdrawn from wholesome duties to minister to the caprices of hysterical selfishness is the person of a household who feels most for the invalid, and who, for this very reason, suffers the most. The patient has pain, a tender spine, for example; she is urged to give it rest. She cannot read; 
the self-constituted nurse reads to her. At last light hurts her eyes; the mother remains shut up with her all day in a darkened room. A draught of air is supposed to do harm, and the doors and windows are closed, and the ingenuity of kindness is taxed to imagine new sources of like trouble, until at last the window cracks are stuffed with cotton, the chimney stopped, and even the keyhole guarded. It is easy to see where all this leads to-the nurse falls ill, and a new victim is found. I have seen a hysterical anæmic girl kill in this way three generations of nurses. If you tell the patient she is basely selfish, she is probably amazed, and wonders at your cruelty. To cure such a case, you must morally alter as well as physically amend, and nothing less will answer. The first step needful is to break up the companionship, and to substitute the firm kindness of a welltrained hired nurse."

"Medical opinion," Dr Mitchell goes on to say, "must, of course, vary as to the causes which give rise to the familiar cases I have so briefly sketched. In fact, they vary endlessly; but I imagine that few physicians placed face to face with such cases would not feel sure that if they could give the patient a liberal gain in fat and in blood they would be certain to need very little else, and that the troubles of stomach, bowels, and uterus would speedily vanish. Such certainly has been the result of my own very ample experience. If I succeed in first altering the moral atmosphere, which has been to the patient like the very breathing of evil, and if I can add largely to the weight and fill the vessels with red blood, I am usually sure of giving relief. If I fail, it is because $I$ fail in these very points, or else because $I$ have overlooked or undervalued some serious organic tissue change."

"The treatment I am about to describe consists in seclusion, certain forms of diet, rest in bed, massage (or manipulation), and electricity; and I desire to insist anew on the fact that it is the use of these means together that is wanted."

The means of treatment thus enumerated are described in detail and at some length in separate chapters. We shall endeavour to give a brief account of them, being impressed with their therapeutic value and importance.

Seclusion is evidently, in many cases, almost essential. When a patient, who is weak, thin-blooded, emotional, and to whom a state of delicate health has become a long and, so to speak, cherished habit, is separated from the moral and physical surroundings which have become part of her life, you have effected a great change, which will not only be beneficial in itself, but will greatly aid in the treatment which is to follow. As a rule, Dr M. suggests that in summer seclusion is less desirable than in winter, if the patient is strong enough to gain help from change of air.

Rest is regarded as equally important with seclusion-in some respects more essential. The question whether we shall ask a 
patient to walk or to take rest turns up every day

"Most often we incline to insist on exercise, and are led to do so from a belief that women walk too little, and that to move about a good deal every day is good for everybody. I think we are as often wrong as right." There are self-indulgent people who require to be roused from their tendency to indolence. If you find a woman who has a good colour and is well nourished, who is able always to do what it pleases her to do, and who is tired by what does not please her, order her out of bed and control her with firmness. But there are many cases such as those already described morally like the preceding, but physically indicating great and decided defects of nutrition, in which no sensible man would urge exertion as a means of cure. The time for that may come; but it must follow a prolonged season of entire rest, with the other means still to be considered. In short, patients belonging to the one class must walk; the others should not, until their state of nutrition has been bettered.

Every grade of rest may be recommended, from repose on a sofa for some hours daily to entire rest in bed; but Dr. Mitchell, in carrying out his general plan of treatment, is in the habit of asking his patients to remain in bed from six weeks to two months. At first, and sometimes for four or five weeks, the patient is not permitted to sit up or to sew, or write, or read. The moral influence of absolute repose is found to be of use. women often take to it in a kindly manner. "From a restless life of irregular hours, and probably endless drugging, from heartful sympathy and over-zealous care, the patient passes to an atmosphere of quiet, to order and control, to the system and care of a thorough nurse, to an absence of drugs, and to simple diet. 'The result is always at first, whatever it may be afterwards, a sense of relief, and a remarkable and often quite abrupt disappearance of many of the nervous symptoms with which we are all of us too sadly familiar."

Under the head of rest, the mode in which it does good is very intelligently considered in accordance with physiological principle. Our space forbids us from going into this subject, but the chapter will repay perusal.

The next chapter, as the author remarks, might. have been labelled, "How to deprive rest of its evils." "The two expedients by which he has learned to use prolonged rest without doing harm are massage and electricity. Massage (manipulation): we do not know the origin of the name, but the process is thus described:"An hour is chosen midway between two meals, and the patient lying in bed, the manipulator starts at the feet, and gently but firmly pinches up the skin, rolling it lightly between his or her fingers, and going carefully over the whole foot; then the toes are bent and moved about in every direction, and next with the thumbs and fingers the little muscles of the foot are kneaded and pinched 
more largely, and the interosseous groups worked at with the finger tips between the bones. At last the whole tissues of the foot are seized with both hands and somewhat firmly rolled about. Next the ankles are dealt with in like fashion, all the crevices between the articulating bones being sought out and kneaded, while the joint is put in every possible position. The leg is next treated, first by surface-pinching, and then by deeper grasping of the areolar tissue, and last by industrious and deeper pinching of the larger muscular masses, which for this purpose are put in a position of the utmost relaxation."

A similar process is carried on in the hand, arm, and all the muscles of the body, back, loins, and abdomen. The principle of treatment must be kept in view, viz., to promote the healthy nutrition of the muscular system and to favour the flow of venous blood-currents. After the first few days, advantage is believed to accrue by keeping the part rubbed lubricated with cocoa oil or vaseline.

The daily massage is kept up for six weeks, and then, if things are proceeding favourably, half of the hour is spent in exercising the limbs as a preparation for walking; movements of flexion and extension being made which the patient is expected to resist. Some curious tabular information is given regarding the effects of manipulation on the temperature.

A chapter follows on electricity as another means made use of for the purpose of exercising muscles in persons at rest. In order to do this with the least amount of pain and annoyance, Dr Mitchell makes use of an induction current, with interruptions as slow as one in every two or five seconds. The poles, covered with wellwetted sponges, are placed on each muscle in turn, and kept about four inches apart. Of the four means, rest, seclusion, massage, and electricity, if one is to be left out, he has no hesitation in saythat it should be electricity.

The next chapter is entitled, Dietetics and Therapeutics.

In the case of anæmic patients, occasionally met with, after putting the patients at absolute rest in bed, he places them on a diet of skimmed milk, which will sometimes thin them at the rate of about half-a-pound daily. Two quarts of the skimmed milk daily, given at intervals of two hours, will usually sustain the weight. Beef-soup may be substituted for a day at a time, to obviate the disgust occasioned by the milk.

In the case of a person, thin-blooded, feeble and lacking flesh, having made sure that there is no grave uterine, renal, or pulmonary affection, we separate the woman from her friends, we put her at entire rest in bed, and then get her by degrees on a milk diet. We thus know with precision the amount of food taken. It dismisses as if by magic all symptoms of dyspepsia. It is a great aid towards getting rid of chloral, bromides, morphia, and stimulants.

In a few days a light breakfast is allowed; in a day or two 
more, a mutton-chop is given for dinner, and bread and butter twice or thrice a day. The milk allowance goes on. A wise remark is made at this point. "People who will eat very little if they feed themselves, often take a large amount when fed by another; and, as I have said before, nothing is more tiresome for a patient flat on her back to cut up her food, and to use the fork and spoon. By the plan of feeding we thus gain doubly."

So soon as the patient begins to take other food than milk, $\mathrm{D}$. Mitchell gives iron. He prefers the old subcarbonate of the U. S. Pharmacopia in pretty large dosês. If the bowels are constipated, a pill, with quarter of a grain of watery extract of aloes and two grains of dried ox-gall may be given twice or thrice a day.

When the full dietetic treatment has been reached, and kept up for a few days, we must watch the urine carefully. If urates are precipitated, the amount of nitrogenous food should be lessened, until the urine is again free from sediment.

A number of very successful cases are given, showing, as we think very indisputably, that the plan recommended and so carefully expounded, has strong claims upon the attention of the profession. The volume we have reviewed is unpretentious, the result evidently of much careful clinical observation, and at the same time very apt to be overlooked in these days of rapid driving and hot haste. This is our reason for bestowing upon it more time and space than its size might seem to demand.

\section{Clinical Lectures on Stricture of the Urethra and other Disorders of} the Urinary Organs. By R. Harrison, F.R.C.S. (Churchill).

Is book-writing, as in more important matters, fashions change. There are conservative authors and liberal authors, leaders and followers of both classes. The issue of monographs is a thing of the past; compilations, except they present some novelty in design or arrangement, are not countenanced. The easy access to publicity afforded by our present weekly and monthly issues have snuffed out the good old quarterlies, while a dead weight is brought to bear on succinct treatises by fifteen-volumed encyclopædias.

The work before us pretends to be neither exhaustive of the subjects treated of, nor to serve as a book of reference. It expresses the author's views, and criticises some of those enunciated by other surgeons, "upon points of practice which are still open to discussion and consideration." Mr Harrison's style affords easy and pleasant reading, his opinions are based on 'practice and illustrated by cases,' and he shows thorough conversance with the novelties from time to time proposed for the treatment of diseases of the urinary organs. Books of this class, and in equally good form, on single classes or groups of diseases, are much needed.

voL. XXIv.-No. I. 